\title{
Preparation and In vitro Evaluation of Mucoadhesive Tablets of Montelukast Sodium
}

\author{
Farzana Akter Bithi, Tushar Saha, Nusrat Ahmed, Ikramul Hasan and Md. Selim Reza \\ Department of Pharmaceutical Technology, Faculty of Pharmacy, University of Dhaka, \\ Dhaka-1000, Bangladesh
}

Received: January 24, 2017; Accepted: February 09, 2017; Published (Web): July 31, 2017

\begin{abstract}
Mucoadhesive tablets of montelukast sodium were prepared in order to release the drug for a prolonged period of time so as to reduce the frequency of administration. Direct compression technique was applied using the mucoadhesive polymers which were Methocel K4M CR, Methocel K15M CR, Methocel K100M CR and Eudragit RLPO. Highest percent release of drug after 8 hours was 76\% for Methocel K4M CR, 72.13\% for Methocel K15M CR, 65.68\% for Methocel K100M CR, 65.53\% for the combination of Methocel K15M CR and Eudragit RLPO. Higuchi, Krosmeyer-Peppas was the best fitted model for drug release. The Methocel K15M CR containing drug showed good mucoadhesive strength. The highest ex-vivo mucoadhesive strength and ex-vivo residence time were observed with Methocel K15M CR and Eudragit RLPO combination. Fourier transform infrared (FT-IR) spectroscopy revealed the compatibility of drug with the polymers.
\end{abstract}

Key words: Direct compression, drug release, mucoadhesive polymers, mucoadhesive strength.

\section{Introduction}

Montelukast which is a selective antagonist of leukotriene receptors can be used to lower blood pressure and to treat asthma, allergic rhinitis, heart attack as well as arthritis (Wang et al., 2017; Walia et al., 2006). Montelukast is used as the sodium salt, but doses are expressed in terms of the base; Montelukast Sodium $10.37 \mathrm{mg}$ is equivalent to about $10 \mathrm{mg}$ of Montelukast and the bioavailability of Montelukast is almost 62\% (Zhao et al., 1997). Metabolism occurs through liver P450 (CYP) 3A4 and 2CP microsomes, with potent inhibition of P450 2C8. Excretion happens almost exclusively in bile having a half-life from 2.7 to 5.5 hours in healthy adults. The pharmacokinetic profile is almost similar in females and males, young and adults. In patients with mild to moderate hepatic insufficiency, dosage adjustment is not required but data is insufficient regarding severe hepatic impairment. Montelukast and its metabolites are mainly excreted in bile and not urine, and it therefore has not been evaluated in patients having renal insufficiency. Hepatic first pass metabolism is the main drawback of conventional Montelukast sodium and sustained release formulation of Montelukast sodium is needed for that reason (Panchal et al., 2012). Controlled or sustained release drug delivery systems have advantages as it reduces side effects, hepatic first pass effect and dosing frequency. Bioavailabilty enhancement and localized treatment can also be possible (Panchal et al., 2012). Mucoadhesive drug delivery system using mucoadhesive polymers may be an effective way to sustain the drug release (Madgulkar et al., 2008). Mucoadhesive polymers attach with the mucus by several process which can be explained by wetting theory, electronic theory, adsorption theory, fracture theory and diffusion theory (Boddupalli et al., 2010). Different grades of Methocel which is actually hydroxylpropylmethylcellulose derivatives are widely used as mucoadhesive polymers along with Eudragit which is acrylic acid derivatives. Adsorption can be enhanced by using mucoadhesive 
polymers in formulation as they change the permeability of mucosal membrane or tissues. Furthermore, the interaction between mucoadhesive formulations and mucosal surface offers prolonged residence time of the dosage form at the site of application, thereby reducing the dosing frequency and increasing patient compliance which is the main objective of this work.

\section{Materials and Methods}

\section{Materials}

Montelukast sodium was received as gift sample from Incpeta Pharmaceuticals Ltd. Bangladesh. Merhocel K4M, Methocel K15M, Methocel K100M and Starch 1500 were obtained from Colorcon, USA.
Eudragit RLPO was obtained from Evonik Industries and magnesium stearate was purchased from local market of Dhaka, Bangladesh.

\section{Methods}

Preparation of matrix tablets: Drug, polymer and other excipients were weighed separately according to proposed formulations shown in table 1 . active ingredient (Montelukast sodium) and other excipients were blended for 15 minutes and then taken in the hopper and the die and punch were adjusted to get desired weight of the tablet. After compression the tablets were weighed and tablet weight was measured. Tablets were prepared by direct compression method (Thoorens et al., 2014).

Table 1. Composition of mucoadhesiveMontelukast Sodium (MONT.) tablets.

\begin{tabular}{ccccccccc}
\hline $\begin{array}{c}\text { Formulation } \\
\text { Code }\end{array}$ & $\begin{array}{c}\text { MONT. } \\
(\mathrm{mg})\end{array}$ & $\begin{array}{c}\text { Methocel } \\
\text { K15M } \\
(\mathrm{mg})\end{array}$ & $\begin{array}{c}\text { Methocel } \\
\text { K4M } \\
(\mathrm{mg})\end{array}$ & $\begin{array}{c}\text { Methocel } \\
\text { K100M } \\
(\mathrm{mg})\end{array}$ & $\begin{array}{c}\text { Eudragit } \\
\text { RLPO } \\
(\mathrm{mg})\end{array}$ & $\begin{array}{c}\text { Starch } \\
1500 \\
(\mathrm{mg})\end{array}$ & $\begin{array}{c}\text { Magnesium } \\
\text { Stearate } \\
(\mathrm{mg})\end{array}$ & $\begin{array}{c}\text { Total } \\
\text { weight } \\
(\mathrm{mg})\end{array}$ \\
\hline F1 & 10 & 40 & - & - & - & 70 & 0.12 & 120 \\
F2 & 10 & 50 & - & - & - & 60 & 0.12 & 120 \\
F3 & 10 & 60 & - & - & - & 50 & 0.12 & 120 \\
F4 & 10 & - & 60 & - & - & 50 & 0.12 & 120 \\
F5 & 10 & - & 70 & - & - & 40 & 0.12 & 120 \\
F6 & 10 & - & 80 & - & - & 30 & 0.12 & 120 \\
F7 & 10 & - & - & 50 & - & 60 & 0.12 & 120 \\
F8 & 10 & - & - & 60 & - & 50 & 0.12 & 120 \\
F9 & 10 & 25 & - & - & 15 & 70 & 0.12 & 120 \\
F10 & 10 & 30 & - & - & 20 & 60 & 0.12 & 120 \\
F11 & 10 & 35 & - & - & 25 & 50 & 0.12 & 120 \\
\hline
\end{tabular}

Measurement of thickness:Thickness gauge was used to measure the thickness of tablets. Five tablets from each batch were used, and the average value is calculated.

Measurement of weight variation: To study weight variation, 20 tablets from each formulation were weighed using an electronic balance and test was performed according to official method of USP pharmacopoeia.

Preparation of calibration curve: Standard Montelukast sodium solution was prepared in concentration range of $(2.5 \mathrm{mcg} / \mathrm{ml}$ to $25 \mathrm{mcg} / \mathrm{ml})$. Then the absorbance of those standard solutions of different concentration was observed in the double beam spectrophotometer (Shimadzu UV) at $283 \mathrm{~nm}$.

Measurement of drug content: Five tablets were weighed accurately and powdered equivalent to 10 mg of Monteluakst sodium was accurately weighed and extracted in $100 \mathrm{ml}$ methanol by shaking for 20 min. After filtration through whatman filter paper no.1 and sufficient dilution with methanol, samples were analyzed spectrophotometrically at $283 \mathrm{~nm}$. 
This procedure was repeated thrice. Amount of drug present was determined from the standard curve of Montelukast sodium in phosphate buffer.

Measurement of swelling study: The swelling properties of tablets were evaluated by determination of percent swelling. Each tablet was weighed $\left(\mathrm{W}_{1}\right)$ and immersed in simulated gastric fluid at $\mathrm{pH} 6.8$ for predetermined times. After immersing the formulation for a fixed period of time, the tablets were wiped off so that excess surface water can be removed by using filter paper and weighed $\left(\mathrm{W}_{2}\right)$.

The swelling index was calculated by the following formula (Hassan et al., 2009).

Swelling Index $=[(\mathrm{W} 2-\mathrm{W} 1) \div \mathrm{W} 1] \times 100$

In vitro dissolution study of mucoadhesive Montelukast tablets: The release rate of Montelukast sodium from mucoadhesive tablets was determined using USP dissolution testing apparatus II (paddle type). The dissolution test was performed using 900 $\mathrm{ml}$ of simulated gastric fluid containing phosphate buffer $\mathrm{pH} 6.8$ at $37 \pm 0.5{ }^{\circ} \mathrm{C}$ and $75 \mathrm{rpm}$. Aliquot volume was withdrawn from the dissolution apparatus hourly for $8 \mathrm{~h}$ and the samples were replaced with fresh dissolution medium. The amount of drug released was determined from the standard calibration curve of pure drug after completing the filtration (Costa, 2001).

Successive fractional dissolution time: $\mathrm{T}_{25 \%}, \mathrm{~T}_{50 \%}$, $\mathrm{T}_{80 \%}$, and MDT were calculated from dissolution data in order to characterize the drug release rate in different experimental conditions (Arefin et al., 2016).

Measurement of ex-vivo mucoadhesive strength: Fresh intestinal mucosa of goat was used to perform ex vivo mucoadhesive strength. Mucosal membrane was separated by removing the underlying fat and loose tissues. The membrane was cleaned with distilled water and then divided into pieces. A piece of intestinal mucosa was pasted to a Petri dish by the help of cyanoacrylate adhesive and the it was wetted with 2-5 drops of 6.8 phosphate buffer media and the test was carried out by using the weight.

Measurement of ex-vivo residence time: The ex vivo residence time was determined using a modified
USP disintegration apparatus, which gave an idea about in vivo retention time.

For this study the time for complete erosion or detachment of the tablet from the mucosal surface was recorded as the mucoadhesion time. The total experiment was carried out for 6 hours to see the retention time and correlate this value with the sustaining property of the formulation.

Drug compatibility study with polymers: Fourier transform infrared spectroscopy (FTIR) was performed for checking any interaction between drug and polymer (Balpande, 2013). For this purpose Fourier transform infrared spectroscopic (FTIR) study was conducted for pure drug (Montelukast sodium), Methocel K15M CR, Methocel K4M CR, Methocel K100M, Eudragit RL PO, Formulation F-6 and physical mixture of drug and polymers.

\section{Results and Discussion}

Physical properties of mucoadhesive Montelukast Sodium tablets: The physical parameters of mucoadhesive Montelukast sodium tablets (Table 2) were performed and all the data were within the USP pharmacopoeia limit.

Percent hydration of mucoadhesive Montelukast Sodium tablets: Percent hydration of mucoadhesive Montelukast tablets were observed for 8 hours (Table 3 ) and highest percent hydration value was obtained for F-9 formulation and the lowest percent hydration was obtained for formulation F-4.

In vitro dissolution and kinetic studies of mucoadhesive Montelukast sodium tablets: Formulation F1- F11 was evaluated for dissolution pattern. Various kinetics treatments were investigated to find out their release pattern (Figure 2). All the formulations F1-F11 were checked for dissolution pattern (Table 4). The highest percent release of drug after 8 hour was $76.0 \%$ from F-4. Best fitted model for this formulation was Higuchi $\left(\mathrm{R}^{2}=0.976\right)$, Korsmeyer-Peppas $\left(\mathrm{R}^{2}=0.956\right)$. The release mechanism of this formulation followed Case I, QasiFickian transport Fickian transport (Table 5). On the other hand, the lowest percent release of drug after 8 hour was 58.5\% which was obtained from 
F-11. Best fitted model for this formulation was Higuchi $\left(\mathrm{R}^{2}=0.963\right)$, Korsmeyer-Peppas $\left(\mathrm{R}^{2}=0.930\right)$.
The release mechanism of this formulation followed Anomalous / non- Fickian transport.

Table 2. Physical properties analysis of mucoadhesive Montelukast sodium (MONT.) tablets.

\begin{tabular}{|c|c|c|c|c|c|}
\hline Formulation code & $\begin{array}{l}\text { Average weight } \\
\text { (mg) }\end{array}$ & Diameter & Thickness & $\begin{array}{l}\text { Hardness } \\
\left(\mathrm{kg} / \mathrm{cm}^{2}\right)\end{array}$ & $\begin{array}{c}\text { Friability } \\
(\%)\end{array}$ \\
\hline F-1 & $120 \pm 0.10$ & \multirow{11}{*}{$7.2 \pm 0.5$} & $3.3 \pm 0.01$ & $3.23 \pm 0.05$ & 0.16 \\
\hline F-2 & $119 \pm 1.06$ & & $3.2 \pm 0.02$ & $3.12 \pm 0.04$ & 0.42 \\
\hline F-3 & $119 \pm 0.15$ & & $3.3 \pm 0.02$ & $3.10 \pm 0.01$ & 0.60 \\
\hline $\mathrm{F}-4$ & $119 \pm 0.09$ & & $3.2 \pm 0.02$ & $3.60 \pm 0.01$ & 0.82 \\
\hline F-5 & $120.38 \pm 0.05$ & & $3.3 \pm 0.02$ & $5.50 \pm 0.05$ & 0.00 \\
\hline F-6 & $121.54 \pm 0.15$ & & $3.3 \pm 0.02$ & $3.23 \pm 0.05$ & 0.16 \\
\hline F-7 & $121.85 \pm 0.05$ & & $3.2 \pm 0.03$ & $3.10 \pm 0.01$ & 0.33 \\
\hline F-8 & $118.67 \pm 1.10$ & & $3.3 \pm 0.02$ & $3.00 \pm 0.00$ & 0.08 \\
\hline F-9 & $121.70 \pm 0.15$ & & $3.2 \pm 0.03$ & $4.00 \pm 0.01$ & 0.08 \\
\hline F-10 & $121.18 \pm 0.05$ & & $3.3 \pm 0.01$ & $4.2 \pm 0.05$ & 0.00 \\
\hline F-11 & $120.30 \pm 0.10$ & & $3.2 \pm 0.02$ & $3.12 \pm 0.04$ & 0.24 \\
\hline
\end{tabular}

Table 3. Precent hydration of mucoadhesive tablets of Montelukast sodium.

\begin{tabular}{cccccc}
\hline Formulation code & \multicolumn{5}{c}{ Percent hydration } \\
\cline { 2 - 6 } & $1 \mathrm{hr}$ & $2 \mathrm{hr}$ & $4 \mathrm{hr}$ & $6 \mathrm{hr}$ & $8 \mathrm{hr}$ \\
\hline F-1 & 46.2 & 55.7 & 62.1 & 65.4 & 68.2 \\
F-2 & 43.9 & 53.9 & 60.3 & 64.3 & 67.3 \\
F-3 & 40.8 & 50.2 & 59.5 & 61.4 & 65.8 \\
F-4 & 38.3 & 48.6 & 58.6 & 60.1 & 63.9 \\
F-5 & 47.6 & 60.5 & 66.1 & 70.2 & 80.3 \\
F-6 & 47.9 & 57.3 & 65.2 & 68.3 & 74.7 \\
F-7 & 47.8 & 56.2 & 63.7 & 67.2 & 72.4 \\
F-8 & 48.9 & 53.7 & 60.2 & 65.4 & 70.3 \\
F-9 & 45.6 & 60.3 & 67.52 & 69.23 & 81.20 \\
F-10 & 47.2 & 54.7 & 60.5 & 71.4 & 73.1 \\
F-11 & 42.7 & 55.9 & 67.2 & 76.3 \\
\hline
\end{tabular}

Table 4. Release rate constants and $\mathrm{R}^{2}$ values for different release kinetics of different formulation (F1-F11).

\begin{tabular}{ccccccccc}
\hline \multirow{2}{*}{ Formulation Code } & \multicolumn{2}{c}{ Zero order } & \multicolumn{2}{c}{ First order } & \multicolumn{2}{c}{ Higuchi } & \multicolumn{2}{c}{ Korsmeyer-Pappas } \\
\cline { 2 - 9 } & $\mathrm{K}_{\mathrm{o}}$ & $\mathrm{R}^{2}$ & $\mathrm{~K}_{1}$ & $\mathrm{R}^{2}$ & $\mathrm{~K}_{\mathrm{h}}$ & $\mathrm{R}^{2}$ & $\mathrm{n}$ & $\mathrm{R}^{2}$ \\
\hline F-1 & 7.179 & 0.919 & 0.117 & 0.926 & 22.29 & 0.966 & 0.393 & 0.942 \\
F-2 & 06.509 & 0.851 & 0.097 & 0.975 & 21.33 & 0.969 & 0.371 & 0.949 \\
F-3 & 6.410 & 0.919 & 0.097 & 0.937 & 20.09 & 0.958 & 0.390 & 0.930 \\
F-4 & 7.639 & 0.920 & 0.138 & 0.951 & 24.15 & 0.976 & 0.403 & 0.956 \\
F-5 & 6.873 & 0.920 & 0.105 & 0.989 & 21.85 & 0.987 & 0.404 & 0.967 \\
F-6 & 6.577 & 0.905 & 0.101 & 0.957 & 20.81 & 0.961 & 0.382 & 0.923 \\
F-7 & 6.849 & 0.942 & 0.108 & 0.946 & 21.18 & 0.955 & 0.462 & 0.931 \\
F-8 & 6.377 & 0.941 & 0.094 & 0.959 & 19.87 & 0.969 & 0.452 & 0.95 \\
F-9 & 7.098 & 0.951 & 0.110 & 0.983 & 22.12 & 0.980 & 0.472 & 0.953 \\
F-10 & 6.136 & 0.881 & 0.089 & 0.991 & 19.85 & 0.978 & 0.346 & 0.965 \\
F-11 & 6.378 & 0.936 & 0.092 & 0.967 & 19.85 & 0.963 & 0.441 & 0.930 \\
\hline
\end{tabular}


Table 5. The best fitted model and mechanism of drug release from formulations (F1-F11).

\begin{tabular}{clcl}
\hline $\begin{array}{c}\text { Formulation } \\
\text { code }\end{array}$ & Best fitted model & $\begin{array}{c}\text { n value } \\
\text { (Korsmeyer- } \\
\text { Peppas model) }\end{array}$ & Release mechanism \\
\hline F-1 & Higuchi, Korsmeyer-Peppas & 0.393 & Case I, QasiFickian transport Fickian transport \\
F-2 & Higuchi, Korsmeyer-Peppas & 0.371 & Case I, QasiFickian transport Fickian transport \\
F-3 & Higuchi, Korsmeyer-Peppas & 0.390 & Case I, QasiFickian transport Fickian transport \\
F-4 & Higuchi, Korsmeyer-Peppas & 0.403 & Case I, QasiFickian transport Fickian transport \\
F-5 & Higuchi, Korsmeyer-Peppas & 0.404 & Case I, QasiFickian transport Fickian transport \\
F-6 & Higuchi, Korsmeyer-Peppas & 0.382 & Case I, QasiFickian transport Fickian transport \\
F-7 & Higuchi, Korsmeyer-Peppas & 0.462 & Anomalous / non- Fickian transport \\
F-8 & Higuchi, Korsmeyer-Peppas & 0.452 & Anomalous / non- Fickian transport \\
F-9 & Higuchi, Korsmeyer-Peppas & 0.472 & Anomalous / non- Fickian transport \\
F-10 & Higuchi, Korsmeyer-Peppas & 0.346 & Case I, QasiFickian transport \\
F-11 & Higuchi, Korsmeyer-Peppas & 0.441 & Anomalous / non- Fickian transport \\
\hline
\end{tabular}

Table 6. Comparison of ex-vivo mucoadhesive strength, force of mucoadhesion and ex-vivo residence times of different mucoadhesive polymers.

\begin{tabular}{lccc}
\hline Polymers & $\begin{array}{c}\text { Ex-vivo mucoadhesive } \\
\text { strength (gm) }\end{array}$ & Force of mucoadhesion $^{a}$ & Ex-vivo residence time (hr) \\
\hline Methocel K15M CR & 53 & 0.519 & 4.4 \\
Methocel K4M CR & 50 & 0.491 & 4.2 \\
Methocel K100M CR & 45 & 0.441 & 4 \\
Methocel K15M CR + & 75 & 0.735 & 5 \\
Eudragit RLPO & & & \\
\hline
\end{tabular}

$\boldsymbol{a}=($ mucoadhesive strength $\times 0.00981)$

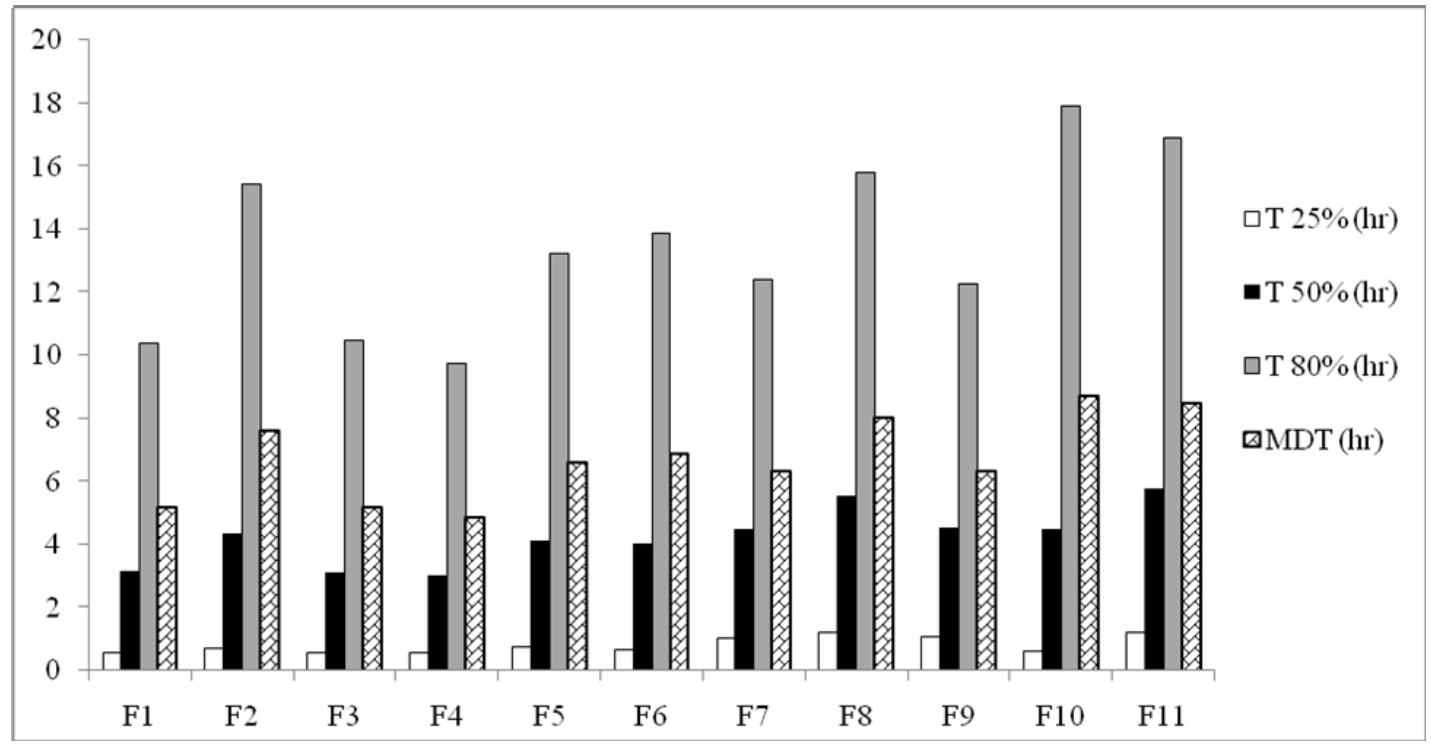

Figure 1. Successive fractional dissolution time of different formulations (F1-F11). 

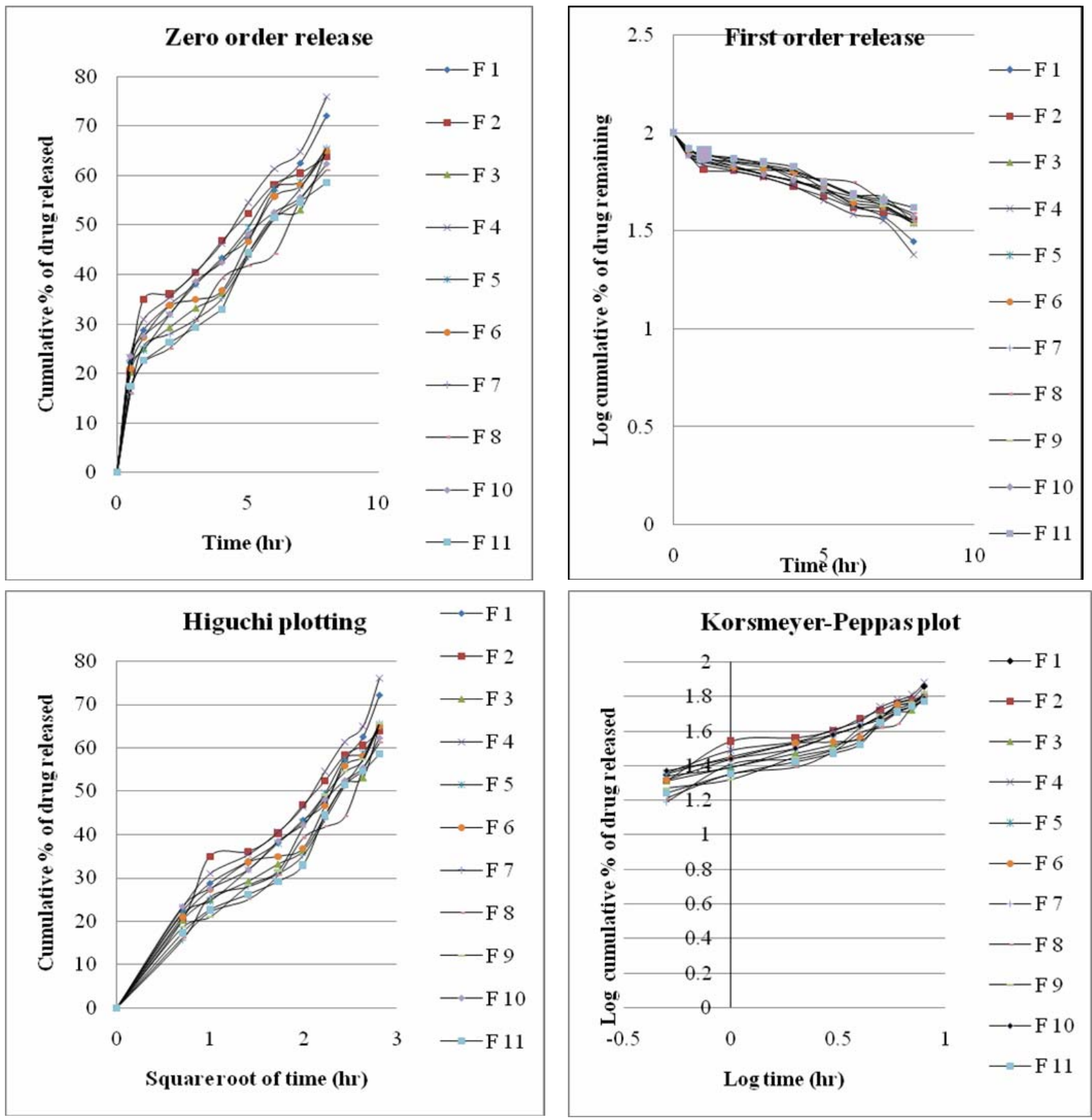

Figure 2. Release kinetics of different formulations (F1-F11) of mucoadhesive Montelukast sodium tablets.

Comparison of ex-vivo mucoadhesive strength, force of mucoadhesion and ex-vivo residence times of different mucoadhesive polymers: Ex-vivo mucoadhesive strength, force of mucoadhesion and ex-vivo residence time were highest for mixture of polymers (Methocel K15M CR \& Eudragit RLPO) and the value was lowest for Methocel K100M CR polymer (Table 6).
Successive fractional dissolution time: From figure 1, successive fractional dissolution time was observed to be highest for F-10 and the values was lowest for F-4. A higher value of MDT indicates a higher retaining ability of the polymer and viceversa. Release retarding capability of the polymers was quite good which was indicated from the figure 1. 
Fourier transforms infrared spectroscopy (FTIR) for compatibility study: Figure 3(A) represents the FTIR spectra of pure Montelukast sodium. In FTIR spectra of pure Montelukast powder the characteristic bands at $3441 \mathrm{~cm}^{-1}(-\mathrm{OH}$ stretching

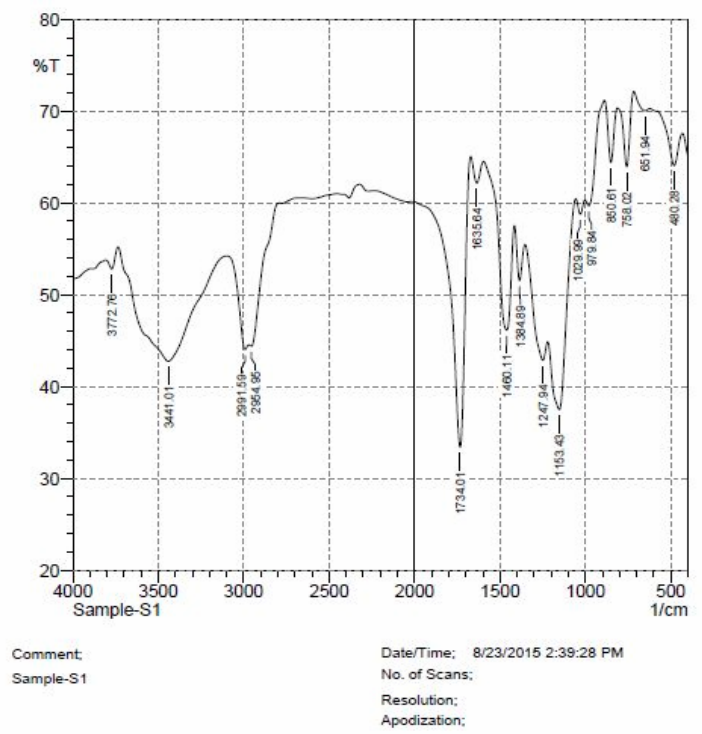

(A) FTIR spectram of Montelukast sodium

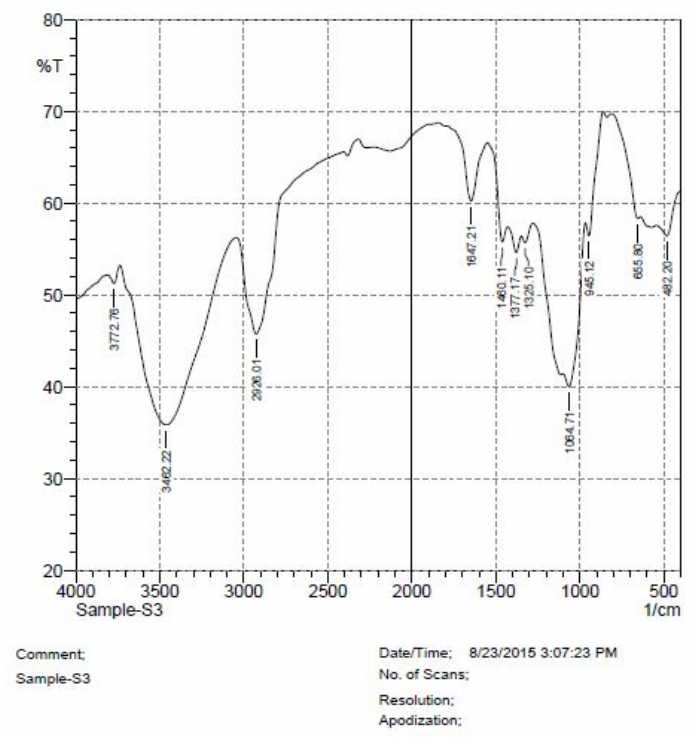

(C) FTIR spectram of Methocel K4M CR vibration), $3058 \mathrm{~cm}^{-1}$ (Aromatic C-H stretching vibration), $2991 \mathrm{~cm}^{-1}$ (Aliphatic C-H stretching vibration), $3058 \mathrm{~cm}^{-1}$ (Aromatic C-H stretching vibration), 1460.11 (Aliphatic $\mathrm{C}-\mathrm{H}$ bending vibration)and 1153.43(-C=O stretchingvibration). $-\mathrm{OH}$

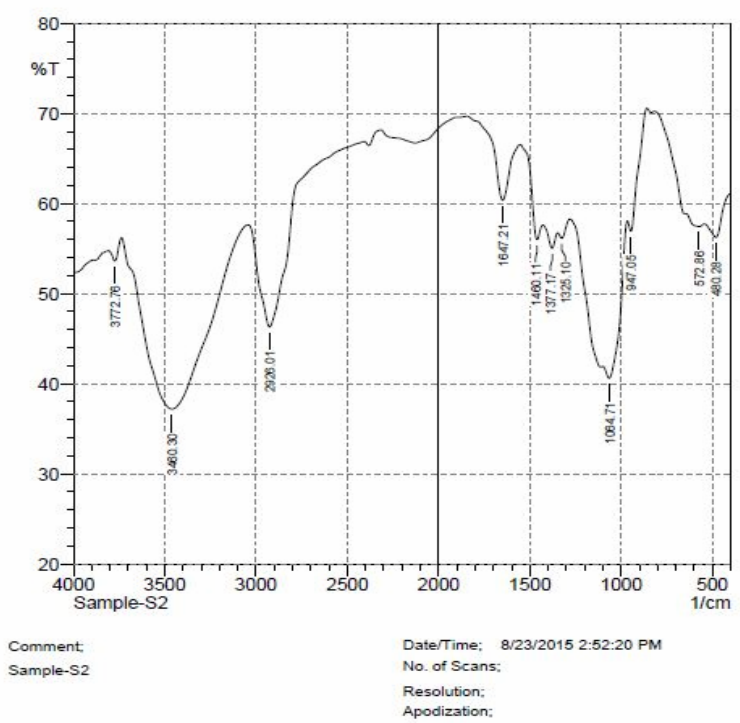

(B) FTIR spectram of Methocel K15M CR

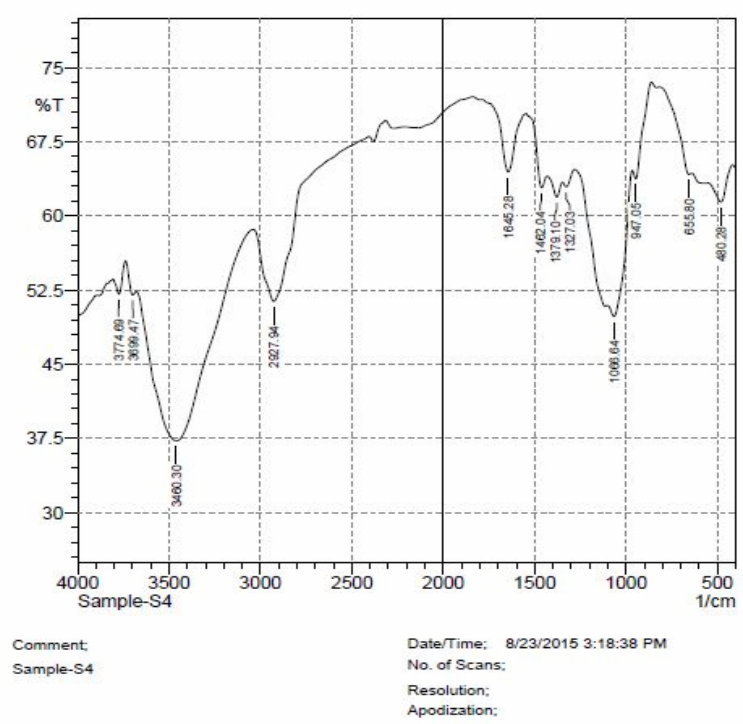

(D) FTIR spectram of Methocel K100M CR

Figure 3 (A) FTIR spectram of Montelukast sodium (B) FTIR spectram of Methocel K15M CR (C) FTIR spectram of Methocel K4M CR (D) FTIR spectram of Methocel K100M CR. 


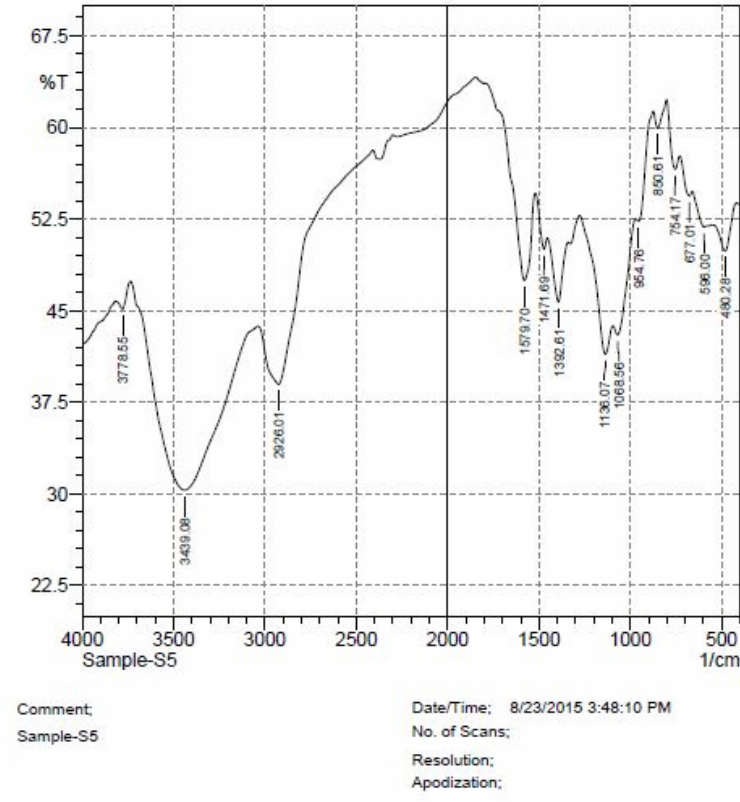

(E) FTIR spectram of Eudragit RLPO

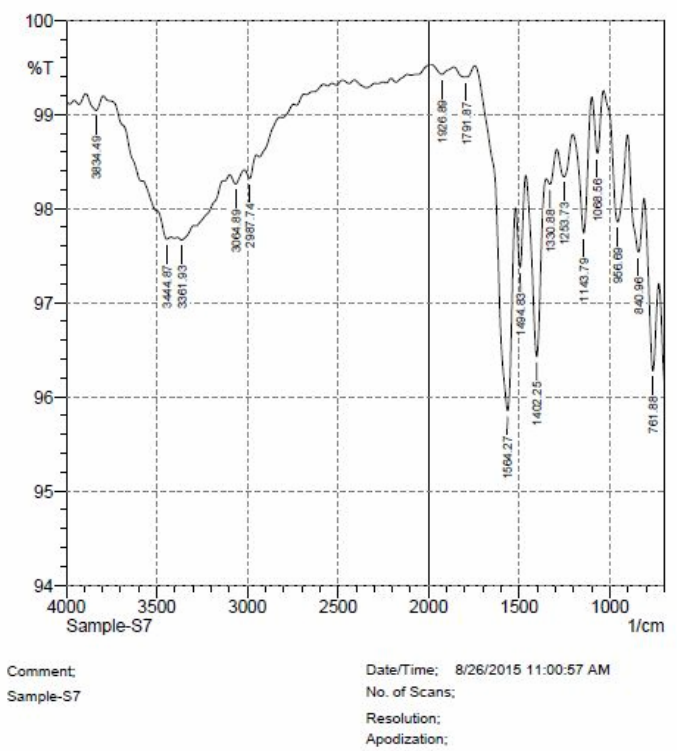

(F) FTIR spectram of drug and polymers mixture (Methocel K4M CR, K100M CR, K15M CR and Eudragit RLPO)

Figure 4. (E) FTIR spectram of Eudragit RLPO (F)FTIR spectram of drug and polymers mixture (Methocel K4M CR, K100M CR, K15M CR and Eudragit RLPO).

stretching vibrations occur at $3392 \mathrm{~cm}^{-1}$. Based on this, in the present investigation, - $\mathrm{OH}$ symmetric stretching vibrations are observed at $3441 \mathrm{~cm}^{-1}$. Aliphatic C-H- stretching vibrations occur at 2975 $\mathrm{cm}^{-1}$ and $2928 \mathrm{~cm}^{-1}$. In present investigation it is observed at $2991 \mathrm{~cm}^{-1}$. C=O stretching vibrations occur at $1144 \mathrm{~cm}^{-1}$. In present investigation it is observed at $1153.43 \mathrm{~cm}^{-1}$.

\section{Conclusion}

The hydrophilic matrix of Methocel and mucoadhesion property of the polymer controls the release effectively for 8 hours. Drug release kinetics indicated that the drug release was best explained by Higuchi equation. The experiment revealed that Methocel K15M and Methocel K4M were more efficient polymer in retarding drug release. The highest mucoadhesive strength was observed with HPMC K15M and Eudragit RLPO combination. Because of its increased concentration and thus the viscosity of the polymer increases, it shows higher strength in combination with Eudragit RLPO.

\section{Reference}

Arefin, P., Hasan, I., Islam, M.S. and Reza, M.S. 2016. Formulation and in vitro evaluation of Eudragit RL 100 loaded Fexofenadine HCL microspheres. Bangladesh Pharm. J. 19, 58-67.

Balpande, H.M., Raut, N.S., Umekar, M.J. and Kotagale, N.R. 2013. Compatibility study of Metformin with pharmaceutical excipients. Int. J. Chem. Tech. Res. 5, 1684-1693.

Boddupalli, B.M., Mohammed, Z.N.K., Nath, R.A. and Banji, D. 2010. Mucoadhesive drug delivery system: An overview. J. Adv Pharm Technol Res. 1, 381-387.

Costa, P. and Lobo, J.M.S. 2001. Modeling and comparison of dissolution profiles. Euro. J. Pharm. Sci. 13, 123133.

Hassan, N., Khar, R.K., Ali, M. Mnd Ali, J. 2009. Development and evaluation of buccal bioadhesive tablet of an anti-emetic agent ondansetron. AAPS Pharm. Sci. Tech. 10, 1085-1092.

Madgulkar, A., Kadam, S. and Pokharkar, V. 2008. Studies on formulation development of mucoadhesive sustained release Itraconazole tablet using response surface methodology. AAPS Pharm. Sci. Tech. 9, 9981005. 
Panchal, R., Patel, H., Patel, V., Joshi, P. and Parikh, A. 2012. Formulation and evalution of Montelukast sodium - chitosan based spray dried microspheres for pulmonary drug delivery. J. Pharm. Bioallied. Sci. 4, 110-111.

Thoorens, G., Krier, F., Leclercq, B., Carlin, B. and Evrard, B. 2014. Microcrystalline cellulose, a direct compression binder in a quality by design environment - A review. Int J. Pharm Sci Res. 473, 64-72.
Wang, D., Zhou, C., Cong, R., Li, Y. and Wang, X. 2017. Simultaneous determination of Montelukast sodium S-enantiomer and A5 enantiomers in Montelukast sodium bulk drug by normal-phase chiral HPLC. Indian J. Pharm. Sci. 79, 139-148.

Walia, M., Lodha, R. and Kabra, S.K. 2006. Montelukast in pediatric asthma management. Indian J. Pediatr. 73, 275-282.

Zhao, J.J., Rogers, J.D., Holland, S.D., Larson, P., Amin, R.D., Haesen, R., Freeman, A., Seiberling, M., Merz, M. and Cheng, H. 1997. Pharmacokinetics and bioavailability of montelukast sodium (MK-0476) in healthy young and elderly volunteers. Biopharm Drug Dispos.18, 769-777. 